\title{
Investigation of early stage deformation mechanisms in a metastable $\beta$ titanium alloy showing combined TWIP and TRIP effects
}

F. Sun ${ }^{a^{*}}$, J.Y. Zhang ${ }^{\mathrm{a}}$, M. Marteleur ${ }^{\mathrm{b}}$, T. Gloriant ${ }^{\mathrm{c}}$, P. Vermaut ${ }^{\mathrm{a}}$, D. Laillec ${ }^{\mathrm{c}}$, P. Castany ${ }^{\mathrm{c}}$, C. Curfs $^{\mathrm{d}}$, P. J. Jacques ${ }^{\mathrm{b}}$ and F. Prima ${ }^{\mathrm{a}}$

a Laboratoire de Physico-Chimie des surfaces, Groupe de Métallurgie Structurale (UMR 7045), Chimie-ParisTech, Paris, France

b Université catholique de Louvain, Institute of Mechanics, Materials and Civil Engineering, IMAP, Place Sainte Barbe 2, B-1348 Louvain-la-Neuve, Belgium

c Institut des Sciences Chimiques de Rennes, UMR CNRS 6226, INSA de Rennes, 20 avenue des Buttes de Coësmes, F-35043 Rennes cedex, France

d European Synchrotron Radiation Facility (ESRF), Grenoble, France

*Corresponding author: Fan SUN

Telephone: + 0033143548702

Fax: + 0033144276710

Laboratoire de Physico-Chimie des Surfaces, (CNRS-UMR 7045) Groupe de Métallurgie

Structurale, ENSCP, 11, rue Pierre et Marie Curie, 75231 Paris cedex 05, France

E-mail: sunfan82@gmail.com

Key words: In-situ synchrotron XRD, Titanium alloy, Deformation twinning, Martensitic 
phase transformation, Deformation mechanism

Abstract

As expected from the alloy design procedure, combined Twinning Induced Plasticity (TWIP) and Transformation Induced Plasticity (TRIP) effects are activated in a metastable $\beta$ Ti-12(wt.\%)Mo alloy. In-situ Synchrotron X-ray diffraction (XRD), electron backscatter diffraction (EBSD) and transmission electron microscopy (TEM) observations were carried out to investigate the deformation mechanisms and microstructure evolution sequence. In the early deformation stage, primary strain/stress induced phase transformations ( $\beta->\omega$ and $\beta->\alpha$ ") and primary mechanical twinning $(\{332\}<113>$ and $\{112\}<111>)$ are simultaneously activated. Secondary martensitic phase transformation and secondary mechanical twinning are then triggered in the twinned $\beta$ zones. The $\{332\}<113>$ twinning and the subsequence secondary mechanisms dominate the early stage deformation process. The evolution of the deformation microstructure results in a high strain hardening rate ( 2GPa) bringing about high tensile strength ( 1GPa) and large uniform elongation (> 0.38).

\section{Introduction}

During the past few decades, the interest for titanium alloys has been continuously increasing due to their combination of properties such as high strength [1-6], low density, biocompatibility [7-10] and good corrosion resistance [11, 12]. However, both their low 
ductility (uniform elongation typically less than 0.20) and their lack of strain-hardening when compared with steels or Co-Cr alloys $[\mathbf{1 1}, \mathbf{1 3}]$, limit the ir use in advanced applications where superior combinations of strength and ductility are required.

A strategy dedicated to a general improvement of the mechanical properties based on transformation induced plasticity (TRIP) or twinning induced plasticity (TWIP) has been widely investigated in the case of steels [14-16]. An optimization of mechanical properties can be also achieved in Ti-based alloys, when controlling the metastability of the $\beta$ matrix through its chemical composition $[\mathbf{4}, \mathbf{5}, \mathbf{1 3}, \mathbf{1 7}, \mathbf{1 8}]$ that strongly influences the martensitic start (Ms) temperature $[5, \mathbf{1 3}, \mathbf{1 9}]$ and the critical resolved shear stress (CRSS) for twinning. Indeed, it has been reported that several deformation induced phase transformations, i.e. $\omega$ phase and $\alpha$ " phase precipitation, and two twinning modes, $\{112\}<111>$ type and $\{332\}<113>$ type, could be activated under different stress conditions (strain rate, temperature, etc.) in some specific Ti alloys [3, 20-25]. These mechanisms can be activated in various alloys exhibiting shape memory effect [19], superelasticity $[\mathbf{1 8 - 2 0}, \mathbf{2 3}, \mathbf{2 4}, \mathbf{2 6}]$ or strain hardening behaviour $[3,4,27$, 28].

Recently, an electronic design approach for the development of a new family of titanium alloys exhibiting a combination of high ductility and improved strain hardening rate has been proposed and exemplified in the binary Ti-12(wt.\%)Mo grade [3, 27]. The chemical formulation of such alloys was designed following the Morinaga model based on the cluster DV-X $\alpha$ method by mapping electronic parameters Bo (bond order) and Md ( $d$-orbital energy) $[29,30]$. This map is of great interest since it can be used as a tool to design new titanium alloys exhibiting specific improved performances. So far, this kind of stability diagrams has 
specially been used for the design of the last generation of low modulus/high strength alloys, such as the "Gum metals" series [31].

In the case of the high strain hardening rate in Ti-12(wt.\%)Mo alloy, the design approach aims at activating simultaneously various deformation modes [27]. It is well known that, in titanium alloys, the main deformation mechanism evolves from dislocation glide to mechanical twinning then to martensitic transformation when the $\beta$ phase chemical stability decreases. Domains corresponding to the transition between these two last deformation modes have then been targeted on the Bo/Md map [27]. Experimental validation of this design procedure was reached with the Ti-12Mo alloy exhibiting true stress - true strain values at necking, of about $1000 \mathrm{MPa}$ and 0.38 , respectively, w ith a large strain hardening rate close to the theoretical limit $[27,32]$. These values of strength and elongation were hardly reached before in BCC alloys. Both mechanical twinning and stress/strain induced phase transformations were observed in deformed samples, in good agreement with the theoretical predictions. However, the sequence of deformation processes, involving both twinning induced plasticity (TWIP) and transformation induced plasticity (TRIP) is still unclear and needs to be investigated in more details to understand the role of the synergy between these mechanisms in the improvement of the strain hardening. As a consequence, the present work focuses on the characterization of the deformation mechanisms of the Ti-12Mo alloy strained from 0 to 0.08 owing to in-situ synchrotron X-ray diffraction (SXRD), electron backscattered diffraction (EBSD) mapping and transmission electron microscopy (TEM). 


\section{Expe rimental}

The binary Ti- $12 \mathrm{wt} . \%$ Mo alloy was processed by the self-consumable melting technique giving an ingot of $9 \mathrm{~kg}$. The chemical composition of the raw ingot is listed in Table 1. Plates of $10 \mathrm{~mm}$ in thickness were cut, followed by solution treatment (ST) at $1173 \mathrm{~K}$ for 30 minutes and water quenching. The specimens were then cold rolled down to $0.5 \mathrm{~mm}$ thick sheets, corresponding to a reduction level of $95 \%$. These sheets were finally recrystallized at $1173 \mathrm{~K}$ for 30 minutes and water quenched to restore a fully $\beta$ state. The mentioned heat treatments were carried out in tubular furnaces under vacuum $\left(10^{-7} \mathrm{mbar}\right)$ to prevent oxidation. In-situ synchrotron X-ray diffraction data were collected at the high resolution beam line ID31 of the European Synchrotron radiation Source (ESRF), Grenoble (France), from a tensile sample with gauge width of $4 \mathrm{~mm}$ and $0.5 \mathrm{~mm}$ in thickness. The incident X-ray wavelength was $0.4 \AA$. Data collection was performed over the angular range $2-14^{\circ}$, with a step size of $0.005^{\circ}$. Nine scanning stages were carried out at room temperature, starting from the unloaded state, then for increasingly loaded states up to a strain of 0.08 and finally after unloading. Analysis of the diffraction patterns consisted in identifying the phases corresponding to the different peaks and then estimating the lattice parameters owing to Pawley refinement using TOPAS [33]. Estimation of the intensity of specific peaks was also carried out.

Cyclic tensile loading/unloading steps were applied to a prior polished sample, bringing about some surface relief related to the activated deformation mechanisms.

Finally, specimens deformed to various strains were also prepared for electron backscattered diffraction (EBSD) and transmission electron microscopy (TEM). Prior to the EBSD 
observations, samples were first mechanically polished down to $1 \mu \mathrm{m}$ and then chemically polished with a solution of $\mathrm{H}_{2} \mathrm{O}_{2}$ and OP-S (Oxide Polishing Suspension from STRUERS, a colloidal silica suspension with a pH of 9.8 and a grain size of about 0.04 micron). EBSD scans were performed using a field emiss ion gun scanning electron microscope operating at $15 \mathrm{kV}$, with step sizes ranging from 0.1 to $0.05 \mu \mathrm{m}$. A JEOL 2000FX transmission electron microscope operating at $200 \mathrm{kV}$ was also used. Thin foils were prepared by twin-jet electro polishing technique using a solution of $4 \%$ perchloric acid in methanol.

\section{Results}

\subsection{Tensile behaviour}

The uniaxial tensile loading curve of solution treated Ti-12Mo specimen is shown in Fig. 1. The true strain/true stress curve exhibits a large uniform elongation close to 0.4 as well as a significant strain hardening rate, much larger than in the case of the conventional titanium alloys $[\mathbf{3 4}, \mathbf{3 5}]$. The corresponding strain hardening rate $(\mathrm{d} \sigma / \mathrm{d} \varepsilon)$ also represented in Fig. 1 illustrates a multi-stage deformation process as classically observed in microstructures exhibiting multiple plasticity phenomena $[\mathbf{1 4 - 1 6 , 3 6}]$. From elastic limit to $\varepsilon=0.1$, there is first a monotonic increase of the strain hardening rate that reaches a maximum value around 2000 $\mathrm{MPa}$, which is close to the theoretical limit of such alloy $(\mathrm{E} / 50)[\mathbf{2 7}, \mathbf{3 2}]$. Three stages of the strain hardening rate are defined in the deformation process (see Fig. 1). Stage I corresponds to the conventional transition between the elastic and plastic regimes. Stage II relates to a large increase of the strain hardening rate from the elastic limit to $\varepsilon=0.1$. The strain hardening then

decreases in Stage III. In previous work on Ti-12Mo, it was shown that two major deformation 
modes [27], martensitic phase transformation and mechanical twinning, are active during stage II and are continuously interacting throughout the plastic deformation range. Therefore, the evolution of the deformation modes in stage II is of great importance in clarifying the origin of the particular strain hardening behaviour and the corresponding large ductility.

\subsection{Synchrotron X-ray Diffraction}

The SXRD patterns corresponding to different strain levels are given in Fig. 2. Diffraction peaks corresponding to additional deformation-induced phases can be noticed on these diffraction patterns (Fig. 2a). Pawley refinement $[37,38]$ was applied on each SXRD pattern for identification and characterization of the phases induced upon deformation. Fig. $2 b$ gives an example of the refinement after unloading, where strong stress or strain-induced martensite (SIM) $\alpha$ " diffraction can be clearly identified. Fig. 2c presents the position and intensity of the major diffraction peaks of $\omega, \alpha$ " and $\beta$ phases. As classically observed for metastable $\beta \mathrm{Ti}$ alloys, the initial ST microstructure of the present Ti-12Mo alloy exhibits some athermal $\omega$ phase together with the $\beta$ matrix. The characterization of this $\omega$ phase is always difficult by conventional XRD technique due to its size and distribution at the nano-scale. Here, the accurate SXRD scans are able to provide precious information on the evolution sequence of this $\omega$ phase in the strained bulk material. The volume fractions of the phases are directly proportional to the integrated intensity of their specific diffraction peaks. Due to the strong orientational preferences of the transformed phases, the in-situ evolution tendency of the transformed phases is qualitatively illustrated by plotting the ir SXRD intensities versus deformation strain. Fig. $2 d$ shows the evolution of the integrated intensity of the (0001) $\omega$ and 
(110) $\alpha " \quad$ characteristic diffraction peaks, illustrating the sequence of appearance/disappearance of the $\omega$ and $\alpha$ " phases. In the initial ST state, the intensity of the $\omega$ peaks is due to the quenched-in athermal $\omega$ precipitates [3]. At the onset of plastic yielding $(\varepsilon=0.5 \%-0.7 \%)$, the $\omega$ intensity exhibits a sudden increase then followed by a decrease. The diffraction peaks of $\omega$ phase start to vanish after $\varepsilon>0.7 \%$ when the SIM $\alpha$ " signature starts to increase monotonically with strain. Finally, the volume fraction of SIM $\alpha$ " phase reaches a maximum at about $8 \%$ strain and displays a reduction after unloading.

\subsection{EBSD and TEM investigations}

EBSD mapping has been performed on specimens strained to different levels, to highlight the complex patterns. No deformation bands were observed by EBSD with its own spatial resolution for specimens strained up to $\varepsilon=0.005$. However, both $\{332\}<113>$ tw ins and SIM $\alpha$ " plates have been observed at $\varepsilon=0.01$, as illustrated on Fig. 3a-d. Fig. 3a shows that two twinning systems are activated from the beginning of plasticity. It is worth noting that twins are not confined into one grain like in TWIP steels $[16,39]$. Indeed, they propagate through grain boundaries to surrounding grains while undergoing a small misorientation corresponding to the one between these neighbouring grains. The width of these twins has been measured and ranges between 600 and $800 \mathrm{~nm}$. In Fig. 3b and d, band contrast and phase identification als o suggest the formation of a three-variant network of SIM $\alpha$ " needles deeper beneath the sample surface with conventional $\alpha " / \beta$ orientation relationship, i.e. $(110)_{\alpha "}$

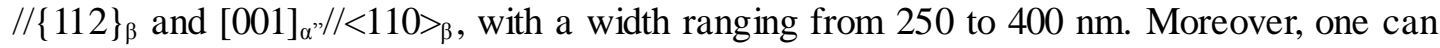
notice a small band of $\alpha$ " phase within the twin indicated by the open arrow in Fig. 3b. This 
phenomenon of $\alpha$ " precipitation within twin bands has been widely observed in specimens strained to larger levels. Fig. $3 \mathrm{c}$ and d illustrate the complexity of the deformation features in this alloy at a strain level as small as 0.01. SIM $\alpha$ " nanoscale precipitates are forming a multi-variant deformation band. Some parts of this band are also indexed as $\beta$ phase, either with the matrix orientation or with a $\{332\}<113>$ twin orientation. This kind of features is more and more observed for increasing strain.

The indexing level decreases very rapidly with strain as illustrated by Fig. 3e and f. Only a few twins and martensitic plates can be indexed on this figure, while most of the deformation areas, e.g. the dark clusters (black arrows) and the interiors of the coarsen bands (open arrows), are left as unidentified.

Fig. 4 show bright and dark field images of a sample deformed to $\varepsilon=0.007$. A set of parallel thin lamella induced by deformation and identified as $\omega$ can be clearly seen The appearance of these bands at the onset of plastic activity is consistent with the synchrotron measurements of Fig.2. It can be observed from the diffraction patterns (inset of Fig. 4b) that one of the two variants of $\omega$ phase is favoured, resulting in an intensity increase of the diffracting spots. The edge-on lamellas are parallel to (1-12) $\beta$ plane.

Fig. 5 shows that the dark clusters (at $\varepsilon=0.015$ ) that were not indexed by EBSD (Fig. 3e) correspond to two sets of acicular plates of $200-300 \mathrm{~nm}$ in thickness indexed as primary $\alpha$ " martensitic plates on the corresponding SAED pattern. Furthermore, Fig. 6 presents a representative example of the complexity of deformed samples, already at $\varepsilon=0.015$. Consistently with EBSD observations (Fig. 3), the diffraction pattern along the $<111>\beta$ zone axis (Figs. 6a and 6c) shows that two kinds of deformation products, i.e. twin and martensite, 
surrounded by the $\beta$ matrix are present. The twinning system is identified as $\{332\}<113>$. Selecting a set of diffraction spots corresponding to $\alpha$ " and twin, dark field image of Fig. $6 \mathrm{~b}$ shows three zones of interest marked as Z1, Z2 and Z3, hightlighed in Fig.7. Figs. 7a and 7b show that two different sets of $\alpha$ " variants can be found. They are present either within twinned $\beta$ (variant $\alpha{ }_{v_{1}}$ in zone Z1) or within the $\beta$ matrix (variant $\alpha{ }^{\prime}{ }_{v 2}$ in zone Z2). The $\alpha{ }_{v_{2}}$ yie lds conventional re lationship with respect to the $\beta$ matrix, i.e. $(-110) \alpha{ }^{\prime}{ }_{2} / /(-112) \beta$, whereas $\alpha{ }{ }_{\mathrm{v} 1}$ accommodates crystallographically to a $\left.\{332\}<113\right\rangle$ twinned $\beta$ zone as $(-110) \alpha{ }_{\mathrm{v}_{1}} / /(-112)_{\mathrm{twin}}$. For convenience, they are called hereafter primary $\alpha "$ martensite and secondary $\alpha$ " martensite, respectively. It can be noticed from this dark field image, that the $\{332\}<113>\beta$ twin are almost completely fulfilled with the $\alpha$ " martensitic phase. In the case of zone Z3 fulfilled with a high volume fraction of stress-induced $\alpha$ " phase, Figs. 7c and 7d show that the martensitic phase is actually internally twinned with the twinning plane identified as $(-110) \alpha{ }{ }_{11}$, bringing about the variants $\alpha{ }_{{ }_{11}}$ and $\alpha{ }_{{ }_{11}}$ as illustrated on the Figs. $7 \mathrm{e}$ and $7 f$.

The bright field image reported on Fig. 8 dis plays some details of the mechanical twins found after a deformation of $\varepsilon=0.005$. The tip section of the $\{332\}<113>$ twin band was examined for microstructural details (Fig. 8c).The magnified image shows a set of alternated matrix and twin zones (indicated by $\mathrm{M}$ and $\mathrm{T}$ ). The micrograph also reveals internal structure composed by plate-like bands of tens of nanometers in size. In order to further investigate the morphologies and interfaces of this phenomenon, the specimen was rotated $\sim 30^{\circ}$ from Fig. $8 \mathrm{a}$ position and tilted $45^{\circ}$ around c-axis of the twin to superimpose the two twinning layers with $[010]_{\mathrm{T}}$ zone-axis. The corresponding [010]ß SAED (inset of Fig. 8d) reveals extra spots due to 
the lamella microstructure. Nano beam diffraction (NBD) analysis of the substructure was performed on/near these internal bands and shows substructures lying in layers with orientations switching from $[010] \beta$ to [1-11] 3 . Such phenomenon can be interpreted from the NBD and the pole figure analysis (Fig. 8f) as a multiple twinning effect in the $\{332\}<113>$ twinning system, with nucleation and growth of a $\{332\}<113>$ type secondary twinning system within the primary twins. The interlayer crystallographic relationship is schematically demonstrated in the superimposed pole figure along $[010] /[1-11] \beta$ zone axis of Fig. 8f. The SAED pattern of this area exhibits a double diffraction effect due to the overlapping interfaces

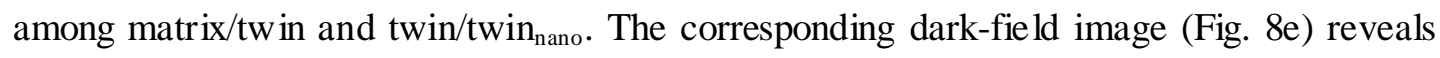
the morphology of nano-size internal twins. A schematic illustration of such structure is shown in Fig.9. The twinning plane between $\mathrm{T}$ and $\mathrm{T}_{\text {nano }}$ shares $(-3-2-3)_{\mathrm{T}}$ plane in $[1-31]_{\mathrm{T}}$ direction, whereas the twinning mode between T/M follows $(3-32)_{\mathrm{T}}[1-1-3]_{\mathrm{T}}$ relationship. The doubled twin plates present an angle of $41.08^{\circ}$ with two twinning vectors not coplanar with each other.

Finally, it is worth noting that the $\{332\}<113>$ twinning system was not the only twinning system found in this alloy since the other well known twinning mode in BCC metals $\{112\}<111>$ was also observed. However, the volume fraction of this twinning mode is very low according to the TEM analysis. This mode will not be discussed in the present paper since it may be of minor importance in the final mechanical properties of the material

\section{Dis cussion}

As expected from the design strategy, the material displays a mechanical behaviour based on 
multiple deformation mechanisms. Regarding the complexity of the deformation process, several characterization techniques have been used in a complementary way to identify the different mechanisms activated during straining. Three main kinds of deformation mechanisms have been shown to be activated: stress induced $\omega$ phase, stress induced $\alpha$ " martensite and mechanical twinning. The conjunction of these deformation mechanisms leads to a complex evolution of the microstructure already in the early stages of deformation.

\subsection{Deformation mechanis ms}

\subsubsection{Deformation induced $\omega$ phase}

Three different ways of $\omega$ precipitation have been reported for titanium alloys: (i) during quenching from the high temperature $\beta$ range owing to a shuffling mechanism (athermal $\omega$ phase); (ii) during low temperature aging, in a process controlled by a diffusion mechanism (isothermal $\omega$ phase); (iii) during straining (deformation induced $\omega$ phase) by shear stress. [40, 41]. Regarding the ST Ti-12Mo material, it is worth noting that the athermal $\omega$ phase is present in the microstructure prior to any deformation. Furthermore, in-situ SXRD (Fig. 2) reveals a slight increase of the $\omega$ volume fraction at the onset of plasticity, followed by its fast disappearance. The TEM investigation of Fig. 4 confirmed the presence of a needle-like $\omega$ phase displaying the typical signature of a shear-induced product in the specimens strained to 0.007 and 0.015 . Since athermal $\omega$ phase is already present in the microstructure prior to deformation, it is important to clarify if the increase of the $\omega$ volume fraction is actually based on nucleation of a new deformation induced $\omega$ phase or on a preferential growth of the existing athermal $\omega$ phase. Experimental evidences of such deformation induced $\omega$ precipitation are 
hardly reported for titanium alloys. However, similar observations were made on Ta based alloys after shock-induced impact deformation [42] and on nanocrystalline Mo based alloys [43] after severe plastic deformation process (high pressure torsion). These investigations revealed that, similarly to deformation twinning, the $<111>$ shear on $\{112\}$ planes may play a major role in the formation of $\omega$ phase. As a consequence, it was shown that this kind of $\omega$ phase can be formed based on a dislocation mechanism during shear deformation [41-43]. The atoms in different planes have to move a distance of $1 / 2$ [111] (layer 2), 1/3[111] (layer 3) and 1/12[111] (layer 4 ) in the transformation process from $\beta$ phase to $\omega$ phase. Therefore, it was demonstrated that the $\omega$ phase could be generated by the glide of partial dislocations of types $1 / 3[111]$, $1 / 6[111]$ and $1 / 12[111]$, which are dissociated from $1 / 2$ [111] perfect dislocations in the BCC structure [44].

The assumption of a preferential growth of the $\omega$ phase induced by an external strain, has been previously simulated by phase field modelling [45].The compressive or tensile stress may modify the equi-probable growth of the four variants of athermal $\omega$ phase. As a consequence, a selective growth of specific variants occurs whereas the other variants are inhibited. Both nucleation and growth mechanisms may lead to a change in the corresponding $\omega$ diffraction intensity (insets of Fig. 4), where $\omega_{1}$ is found to be much stronger than $\omega_{4}$ (diffractions of $\omega_{2}$ and $\omega_{3}$ are not distinguishable from the $\beta$ spots). The alignment of the promoted $\omega$ variants constitutes the deformation induced $\omega$ lamellas (Fig. 4) and results in an increase of the $\omega$ volume fraction, as observed on the SXRD (Fig. 2d).

Concerning the subsequent evolution of $\omega$ phase volume fraction, which is observed to 
decrease from $\varepsilon=0.007$ to $\varepsilon=0.04$, a reasonable explanation can be given, based on shearing and shuffling of the parent $\beta$ lattice. The fact that $\omega$ phase rapidly disappears is probably due to a shear band mechanism. Similarly to the work of Gysler et al. [21], the $\omega$ phase destruction may be due to the intense dislocation slip in the active $\{112\}<111>$ slip system. Therefore, these shear bands $\{112\}<111>$ may destroy all $\omega$ particles within the strain concentrated volume.

\subsubsection{SIM $\alpha$ " trans formation and mechanical twinning}

It is really worth mentioning that SIM and mechanical twinning are triggered simultaneous ly from the onset of plasticity in a deformed BCC alloy since very few examples have been found in the previous studies dealing with TWIP and TRIP effects. However, this situation was expected according to our design strategy of the chemical stability of the $\beta$ phase and is shown to result in large improvement both of tensile ductility and of the strain hardening behaviour. It can be observed from Figs. 3, 5, 6 and 7 that a complex pattern of SIM $\alpha$ " phase is developed upon deformation, both in the matrix and in twins. This result is consistent with previous work reporting the mechanicalactivation of the $\alpha$ " transformation in the range of $7 \%$ to $12 \%$ of molybdenum addition [46] whereas pure twinning deformation mode occurs around $14 \%$ of Mo addition [47]. Since containing less $\beta$-stabilising Mo, the critical stress for the activation of the martensitic transformation in the present Ti-12Mo grade is smaller than in the case of previous work on Ti-14Mo. However, this critical stress is larger than the elastic limit so that no pseudo-elasticity occurs in the first loading from ST state (Fig. 1), but it should be noticed that a reverse transformation from $\alpha "->\beta$ occurs at unloading process (Fig. $2 \mathrm{~d}$ ). While the reversible SIM always causes elastic softening [4] in metastable $\beta$ titanium alloys, 
previous researches $[\mathbf{2 0}, \mathbf{2 7}, \mathbf{3 2}]$ suggest that the SIM activated in the plastic regime is able to increase the strain-hardening rate when compared to typical $\beta+\alpha$ microstructures. In metastable $\beta$ Ti alloys, the activated twinning system shifts from $\{112\}<111\rangle$ to $\{332\}<113\rangle$ when the $\beta$ phase stability decreases $[4, \mathbf{1 7}, \mathbf{2 2}, \mathbf{4 8}, \mathbf{4 9}]$. For example, in a deformed Ti-14Mo single crystal [28], two twinning modes were observed together. However, $\{332\}$ tw ins were observed in a much larger volume fraction when compared to $\{112\}$ twins in that material. In the present Ti-12Mo alloy, due to the higher $\beta$ instability, the transgranular $\{332\}$ tw ins can be seen as the major twinning system, whereas $\{112\}$ twins have been scarcely observed.

With the different deformation mechanisms in Ti-12Mo, i.e. dislocations glide, SIM, $\{332\}$ twinning and $\{112\}$ twinning, an "orientation factor", similar to the well known "Schmid factor", may play a critical parameter for the determination of the resolved shear stress for each deformation mechanism [50]. The preferential activation of a specific deformation mechanism in different $\beta$ grains depends on the crystallographic orientation with respect to the applied shear stress. It is indeed illustrated on the EBSD maps of Figs. 3a-d, where twinning is favoured in grain A while SIM is favoured in grains B and D and both deformation mechanisms are activated in grain C. Furthermore, in-plate substructure composed by SIM and twin is present in grain $C$, suggesting that the twinned $\beta$ zones exhibit a modified orientation factor when compared to the $\beta$ matrix. These twinned zones are then subsequently submitted to their own deformation pathway in which secondary deformation products are favoured. Furthermore, the transformed volume fraction from $\beta$ Twins to secondary SIM $\alpha$ " is much higher (Fig. 3d) than that in grain D (favoured in SIM). Similarly, secondary twinning can also be activated in the primary twins (Figs. 8 and 9), depending on the modified 
orientation factor of the secondary twinning plane in the primary twins. This confinement behaviour suggests a size effect in the nucleation and growth of the deformation products in Ti-12Mo. Depending on the orientation factors of the twinned zones, two configurations can occur: secondary SIM and secondary twinning. These two configurations have been observed by EBSD and TEM (Section 3.3). However, the complexity of the deformation microstructure is far beyond this investigation of the early stages of plasticity, more efforts will be made for further understanding of the material.

\subsection{Activation seque nce}

The establishment of the activation sequence of the different deformation mechanisms is of great importance for the optimization of the macroscopic mechanical performance of the material. A schematic representation of the activation sequence is given in Fig. 10, illustrating the microstructural evolution from the initial ST matrix to the deformed state in the early deformation stages. The initial $\beta$ matrix after the ST process is composed by textured recrystallized $\beta$ grains with quenched-in athermal $\omega$ phase. The $\omega$ phase is the first phase to appear within the $\beta$ matrix strained in tens ion. These $\omega$ precipitates are first promoted and then gradually disappear during subsequent straining as shown both by synchrotron diffraction (Fig. 2). In the meantime, primary deformation mechanisms are activated simultaneously, exhibiting a state with the combination of plate-like $\{332\}<113>$ twins and needle-like SIM $\alpha$ " precipitates. The volume fraction of both primary deformation products increases with strain. The twinning mechanism is shown to dominate the primary deformation regime by forming a transgranular network of tw in bands in the $\beta$ grains. The network of twins is formed at a larger 
scale than that of the SIM assembles (Fig. 3 and 5). After the formation of $\beta$ twins, secondary deformation mechanisms are triggered in the twinned $\beta$ zones. It is thought that the activation of the secondary mechanisms is actually regulated by locally modified orientation factors and probably by size factor in the twinned $\beta$ zones. As observed in the deformed twins, two configurations are found with the activation of either a secondary twinning system or a secondary SIM precipitation. It should be noticed that the secondary deformation mechanis ms are very active in every twinned zone observed in this investigation. This situation could probably due to the size effect of the twinned zone, which promotes the nuc leation and growth of the secondary products. However, the situation seems in contradiction to some previous reports [51-53]. The respective effect of orientation factor and size factor remains unclear regarding the secondary mechanisms in twinned $\beta$ zones.

The present Ti-12Mo alloy is thus characterized by the active competition between various deformation mechanisms from early deformation stages, resulting in a complex network of deformation induced products. Owing to this peculiar plastic activity, the present material exhibits unprecedented strain hardening rate associated with an extremely large ductility, when compared to conventional BCC alloys.

\section{Conclusion}

Combined TWIP and TRIP effects were shown to occur in the metastable $\beta$ Ti-12Mo alloy, as expected from the design strategy. The activated deformation mechanisms at the early stage of 
plasticity are phase transformations, $\beta->\omega$ and $\beta->\alpha$ ", and mechanical twinning, $\{332\}<113>$ and $\{112\}<111>$. The activation sequence of the mechanisms was revealed by means of in-situ investigations and supplementary microstructural analysis. A high strain hardening rate associated to a large ductility result from the peculiar sequence of different deformation mechanisms. The features of the early deformation stage are summarized in the following aspects.

(1) Deformation induced $\omega$ precipitation was observed at the very beginning of the tensile strain, prior to SIM phase transformation and mechanical twinning. The volume fraction of $\omega$ phase reached a maximum value at $\varepsilon=0.005$, then gradually disappeared around $\varepsilon=0.04$. It is thought that the $\omega$ precipitates were dissolved by the dislocation glide on $\{112\}$ slip planes.

(2) Primary mechanical twinning and primary SIM $\alpha$ " precipitation were activated simultaneously at $\varepsilon=0.007$ in the $\beta$ matrix. In the meantime, secondary mechanical twinning and secondary SIM $\alpha$ " precipitation were triggered in the twinned $\beta$ zones. The activation of such in-plate phenomena could probably be due to the modification of orientation factor and size factor in the twinned zones.

(3) The volume fraction of SIM $\alpha$ " precipitates kept increasing during the early plastic deformation regime. However, the primary $\operatorname{SIM} \alpha "$ mechanism was much lower in volume fraction when compared to mechanical twinning. The dominating twinning system was $\{332\}<113>$ in the early stage. The volume fraction of $\{112\}<111>$ twinning system was very limited.

Acknowledgments 
P.J. Jacques acknowledges the FRS-FNRS. This work was partially carried out in the framework of the IAP7/21 program of the Belgian Science Policy.

\section{References}

[1] Avery D, Polan N. Metall Mater Trans B 1974;5:1159.

[2] Hao YL, Zhang ZB, Li SJ, Yang R. Acta Mater 2012;60:2169.

[3] Sun F, Prima F, Gloriant T. Mater Sci Eng A 2010;527:4262.

[4] Hao YL, Li SJ, Sun SY, Zheng CY, Yang R. Acta Biomater 2007;3:277.

[5] Hao YL, Li SJ, Prima F, Yang R. Scripta Mater 2012;67:487.

[6] Sun F, Hao YL, Zhang JY, Prima F. Mater Sci Eng A 2011;528:7811.

[7] Bedi RS, Beving DE, Zanello LP, Yan Y. Acta Biomater 2009;5:3265.

[8] Kim H-S, Kim W-Y, Lim S-H. Scripta Mater 2006;54:887.

[9] Niinomi M, Kuroda D, Fukunaga K-i, Morinaga M, Kato $Y$, Yashiro T, Suzuki A. Mater Sci Eng A 1999;263:193.

[10] Kuroda D, Niinomi M, Morinaga M, Kato Y, Yashiro T. Mater Sci Eng A 1998;243:244.

[11] Williams JC, Starke Jr EA. Acta Mater 2003;51:5775.

[12] Samuel S, Nag S, Nasrazadani S, Ukirde V, El Bouanani M, Mohandas A, Nguyen K, Banerjee R. J Biomed Mater Res A 2010;94:1251.

[13] Weiss I, Semiatin S. Mater Sci Eng A 1998;243:46.

[14] Jacques PJ, Furnémont Q, Lani F, Pardoen T, Delannay F. Acta Mater 2007;55:3681.

[15] Lani F, Furnémont Q, Van Rompaey T, Delannay F, Jacques PJ, Pardoen T. Acta Mater 2007;55:3695.

[16] Grässel O, Krüger L, Frommeyer G, Meyer L. Int J Plasticity 2000;16:1391.

[17] Hanada S, Izumi O. Metall Mater Trans A 1987;18:265.

[18] Zhang JY, Sun F, Hao YL, Gozdecki N, Lebrun E, Vermaut P, Portier R, Gloriant T, Laheurte P, Prima F. Mater Sci Eng A 2013;563:78.

[19] Kim HY, Ikehara Y, Kim JI, Hosoda H, Miyazaki S. Acta Mater 2006;54:2419.

[20] Grosdidier T, Philippe MJ. Mater Sci Eng A 2000;291:218.

[21] Gysler A, Lutjering G, Gerold V. Acta Metall 1974;22:901.

[22] Hanada S, Ozeki M, Izumi O. Metall Mater Trans A 1985;16:789.

[23] Sun F, Hao YL, Nowak S, Gloriant T, Laheurte P, Prima F. J Mech Behav Biomed 2011;4:1864.

[24] Talling RJ, Dashwood RJ, Jackson M, Dye D. Acta Mater 2009;57:1188.

[25] Hanada S, Izumi O. Metall Mater Trans A 1986;17:1409.

[26] Sun F, Nowak S, Gloriant T, Laheurte P, Eb erhardt A, Prima F. Scripta Mater 2010;63:1053.

[27] Marteleur M, Sun F, Gloriant T, Vermaut P, Jacques PJ, Prima F. Scripta Mater 2012;66:749.

[28] Hida M, Sukedai E, Hen mi C, Sakaue K, Terauchi H. Acta Metall 1982;30:1471.

[29] Abdel-Hady M, Hinoshita K, Morinaga M. Scripta Mater 2006;55:477.

[30] Morinaga M, Yukawa N, Maya T, Sone K, Adachi H. Theoretical design of titanium alloys. Sixth World Conference on Titani um. III;. Cannes; France; : 6-9 June 1988. , 1988. p.1601.

[31] Saito T, Furuta T, Hwang JH, Kuramoto S, Nishino K, Suzuki N, Chen R, Yamada A, Ito K, Seno Y. 
Science 2003;300:464.

[32] Kocks U, Mecking H. Prog Mater Sci 2003;48:171.

[33] Coelho A. TOPAS-Academic, Version 4.1; < http://www.topas-academic.net/>.

[34] Niinomi M. Mater Sci Eng A 1998;243:231.

[35] Niinomi M. J Mech Behav Biomed 2008;1:30.

[36] Renard K, Idrissi H, Schryvers D, Jacques PJ. Scripta Mater 2012;66:966.

[37] Pawley G, Reynolds P, Kjems J, White J. Solid State Commun 1971;9:1353.

[38] Pawley G, Rinaldi R. Acta Crystallogr, Sect. B: Struct Sci 1972;28:3605.

[39] Gutierrez-Urrutia I, Raabe D. Acta Mater 2011;59:6449.

[40] Wood R. Acta Metall 1963;11:907.

[41] Prima F, Debuigne J, Boliveau M, Ansel D. J Mater Sci Lett 2000;19:2219.

[42] Hsiung LM, Lassila DH. Acta Mater 2000;48:4851.

[43] Cheng GM, Yuan H, Jian WW, Xu WZ, Mill ett PC, Zhu YT. Scripta Mater 2013;68:130.

[44] Lasalmonie A, Chaix C. Philos Mag A 1981;44:973.

[45] Tang B, Cui YW, Kou H, Chang H, Li J, Zhou L. Comp Mater Sci 2012;61:76.

[46] Davis R, Flower H, West D. J Mater Sci 1979;14:712.

[47] Takemoto Y, Hida M. Scripta Metall 1991;25.

[48] Besse M, Castany P, Gloriant T. Acta Mater 2011;59:5982.

[49] Grosdidier T, Roubaud C, Philippe M-J, Combres Y. Scripta Mater 1997;36:21.

[50] Bertrand E, Castany P, Péron I, Gloriant T. Scripta Mater 2011;64:1110.

[51] Yu Q, Shan ZW, Li J, Huang X, Xiao L, Sun J, Ma E. Nature 2010;463:335.

[52] Gil F, Manero J, Planell J. J Mater Sci 1995;30:2526.

[53] Aikawa Y, Terai T, Kakeshita T. Grain size effect on martensitic transformation behavior in Fe-Ni invar alloys. Journal of Physics: Conference Series, vol. 165: IOP Publishing, 2009. p.012057.

\section{Figure caption:}

Figure 1. Tensile true strain/ true stress curve of solution treated Ti-12Mo alloy is shown in black line. The corresponding strain hardening rate, $\mathrm{d} \sigma / \mathrm{d} \varepsilon$, is plotted in black circles and the smoothed curve is shown in red. The monotonic raising of strain hardening rate reaches maximum value of about $2000 \mathrm{MPa}$ from elastic limit to $\varepsilon=0.1$, the early stage of the plastic deformation.

Figure 2. In-situ synchrotron x-ray diffraction (SXRD) results. (a) SXRD patterns corresponding to increasing deformation levels. The stress/strain curve is shown in the inset; (b) An example of the final Pawley refinement applied on the SXRD profile after release from $8.0 \%$ strain; (c) The major diffraction peaks of $\omega$ and $\alpha$ " phases as a function of applied strain; (d) The evolution of the 
integrated intensity of the characteristic peaks $(0001) \omega$ and (110) $\alpha$ " as a function of applied strain.

Figure 3. EBSD superimposed band contrast and inverse pole figure maps showing complex deformation patterns within different grains at $\varepsilon=0.01$ and $\varepsilon=0.05$. (a) Two $\{332\}<113>$ twins with different orientations crosses several grains; (b) Needle-like $\alpha$ " martensite grains in the $\beta$ matrix are indicated by a black arrow, while a grain of $\alpha$ " martensite within the twin band is indicated by an open arrow; (c) Several nanoscale $\{332\}<113>$ twins are arranged to form complex deformation bands; (d) Two variants of $\alpha "$ martensite are forming deformation bands while needle-like $\alpha$ " martensite precipitates are indicated by a black arrow; (e) complex deformation pattern presenting $\{332\}<113>$ twins at $\varepsilon=0.05$; (f) Two variants of $\alpha$ " martensite are also present in the complex deformation pattern at $\varepsilon=0.05$.

Figure 4. TEM images of the deformation induced $\omega$ phase at $\varepsilon=0.007$ and $\varepsilon=0.015$. (a) Bright-field image at $\varepsilon=0.007$; (b) Dark-field image of the deformation induced $\omega$ lamellas at $\varepsilon=0.007$; (c) Dark-field image of the deformation induced $\omega$ lamella at $\varepsilon=1.5 \%$. The corresponding diffraction patterns are presented in the insets of each dark-field image, showing a difference of the diffraction intensity between the two variants ( $\omega_{1}$ and $\omega_{4}$ of the 4 variants) of $\omega$ precipitates.

Figure 5. Bright-field TEM image of deformation feature identif ied as a cluster of $\alpha$ " variants. The corresponding SAED pattern is given in the inset.

Figure 6. TEM images of a sample deformed to $\varepsilon=0.015$. (a) Diffraction pattern exhibiting multiple phases; (b) corresponding dark field image of the deformation products by selecting the diffraction spots highlighted on (a). Three morphologies of the deformation products are revealed, 
labeled as Z1, Z2 and Z3. (c) Indexed diagram corresponding to $\{332\} \beta$ twinning, $\omega$ phase and two kinds of $\alpha "$ martensite, noted as $\alpha "{ }_{\mathrm{v} 1}$ and $\alpha "{ }_{\mathrm{v} 2}$.

Figure 7. Detailed TEM micrographs of the zones Z1, Z2 and Z3 indic ated on Figure 6. (a) Dark field image and corresponding diffraction pattern (inset) of zone Z1 showing a $\{332\} \beta$ twin which is almost fulfilled with $\alpha$ " ${ }_{\mathrm{v} 1}$ martensite; (b) Dark field image and corresponding diffraction pattern of zone Z2 showing a plate-like $\alpha{ }^{\prime}{ }_{\mathrm{V} 1}$ martensite with conventional crystallographic relationship to $\beta$ matrix; (c) Dark field image of $\alpha$ " ${ }_{\mathrm{v} 1}$ martensite in zone Z3 presenting a twin relationship; (d) Dark field image of the morphology of the twinned $\alpha$ " ${ }_{\mathrm{V} 1}$ martensite at zone Z3, denoted by $\alpha$ " ${ }_{\mathrm{V} 1 \mathrm{~T}}$; (e) diffraction pattern corresponding to zone Z3 showing the twin relationship between $\alpha$ "v1 and $\alpha$ "v1T; (f) calculated diffraction pattern corresponding to zone Z3 highlighting the conventional $\{110\} \alpha "$ twinning relationship of the martensite.

Figure 8. TEM images of major deformation features. (a) Bright-field image of a set of $\{332\}<113>$ twin bands; (b) The corresponding SAED pattern illustrates twinning plane and twinning axis; (c) The magnified region shows the sub-structures of fine internal bands; (d) Bright-field image of the region after rotating and tilting the specimen. Corresponding SAED pattern is shown in the inset. Nano-beam diffractions (NBD) were performed on the nano-bands indicated by red dots; (e) Dark-field image in twin spot (DF) of the secondary twins marked by $\mathrm{T}_{2 \mathrm{nd}}$; (f) A schematic stereo projection figure to illustrate the crystallographic relationship of internal $\{332\}<113>$ twin layers along zone ax is $[010] / /[1-11]$ beta.

Figure 9. Schematic illustration of the structural relationship between the $\beta$ matrix $(\mathrm{M})$, the $\{332\}<113>$ twin band $(\mathrm{T})$ and nano-size internal twinning lamella $\left(\mathrm{T}_{2 \mathrm{nd}}\right)$. The overlapping of $\mathrm{T}$ 
and $\mathrm{T}_{2 n d}$ contributes to the double diffraction in the SAED pattern.

Figure 10. Schematic illustration of the evolution of the microstructure of the Ti-12Mo alloy when deformed in tension. The activation sequence of different deformation mechanisms are shown from ST state to the early deformation stages (Stages I and II), i.e. deformation induced $\omega$ phase, mechanical twinning and SIM $\alpha$ ". The secondary deformation twins and SIM $\alpha$ " phase are denoted with subscript " 2 nd".

\section{Table list:}

Table 1. Ingot chemical composition (wt.\%) 
Table 1. Ingot chemical composition (wt.\%)

\begin{tabular}{ccccccc}
\hline Mo & $\mathrm{Fe}$ & $\mathrm{H}$ & $\mathrm{O}$ & $\mathrm{N}$ & $\mathrm{C}$ & $\mathrm{Ti}$ \\
\hline 12.3 & 0.02 & 0.004 & 0.06 & 0.004 & 0.011 & Balanced \\
\hline
\end{tabular}




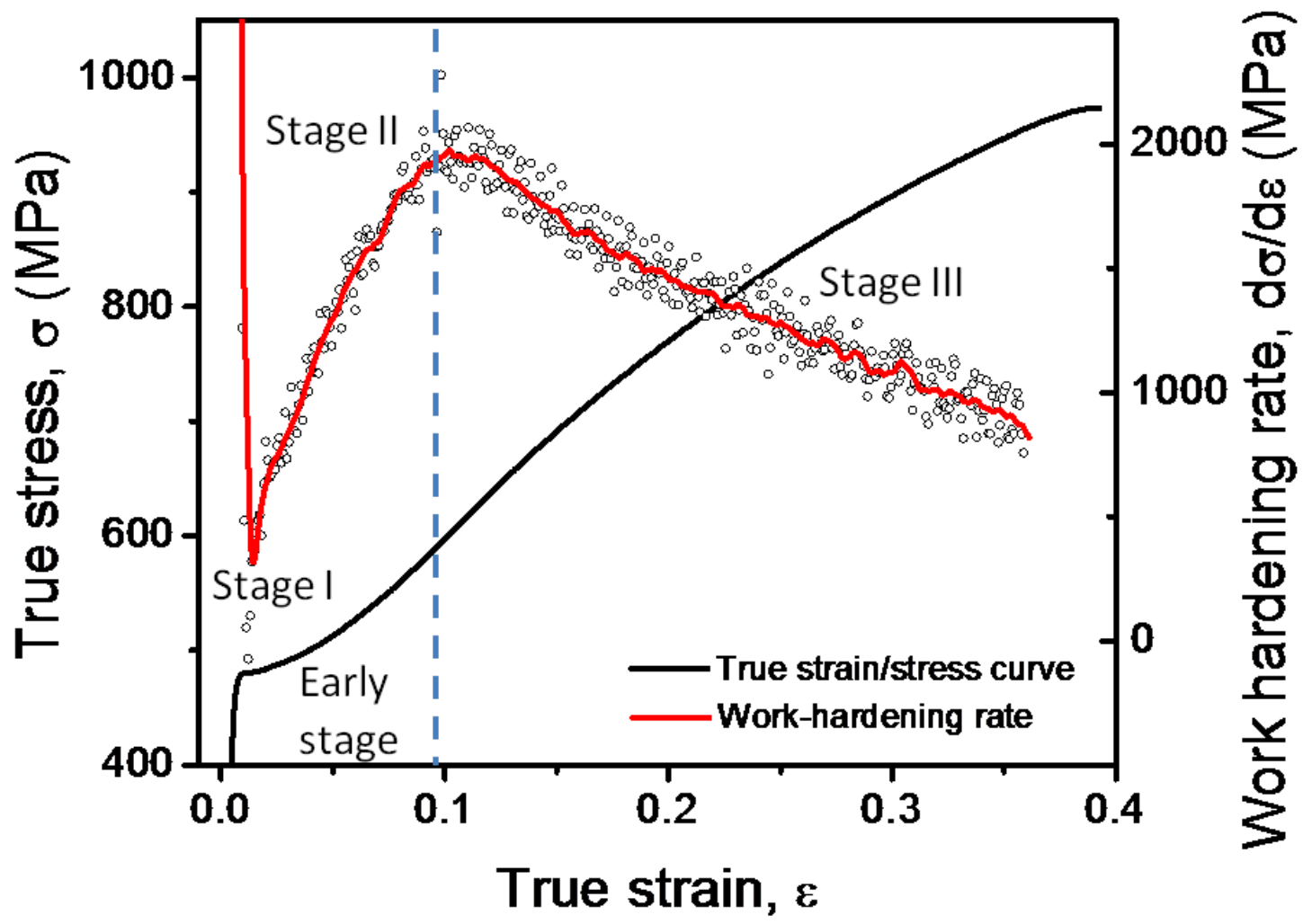

Figure 1. Tensile true strain/ true stress curve of solution treated Ti-12Mo alloy is shown in black line. The corresponding strain hardening rate, $\mathrm{d} \sigma / \mathrm{d} \varepsilon$, is plotted in black circles and the smoothed curve is shown in red. The monotonic raising of strain hardening rate reaches maximum value of about $2000 \mathrm{MPa}$ from elastic limit to $\varepsilon=0.1$, the early stage of the plastic deformation. 

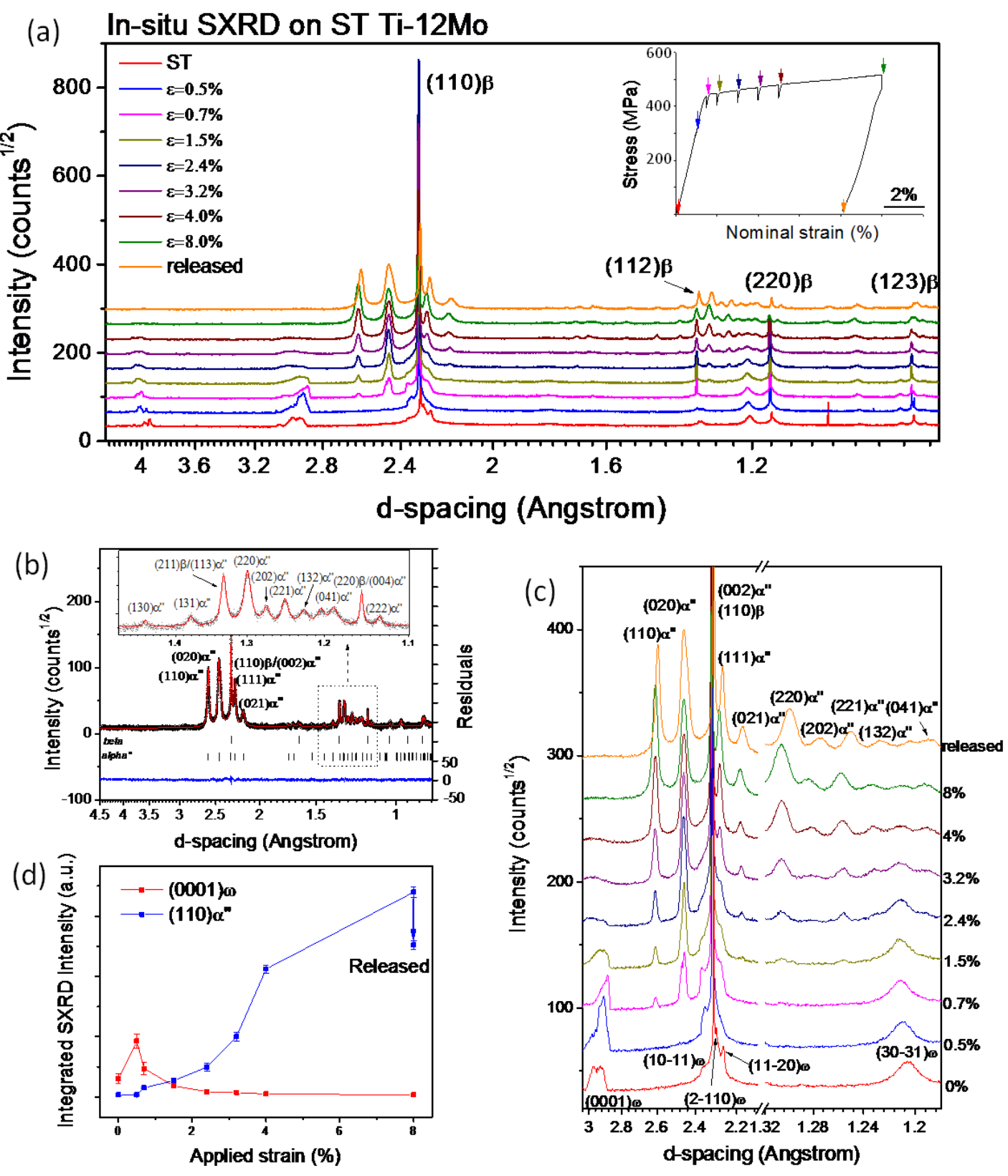

Figure 2. In-situ synchrotron x-ray diffraction (SXRD) results. (a) SXRD patterns corresponding to increasing deformation levels. The stress/strain curve is shown in the inset; (b) An example of the final Pawley refinement applied on the SXRD profile after release from $8.0 \%$ strain; (c) The major diffraction peaks of $\omega$ and $\alpha$ " phases as a function of applied strain; (d) The evolution of the integrated intensity of the characteristic peaks (0001) $\omega$ and (110) $\alpha "$ as a function of applied strain. 


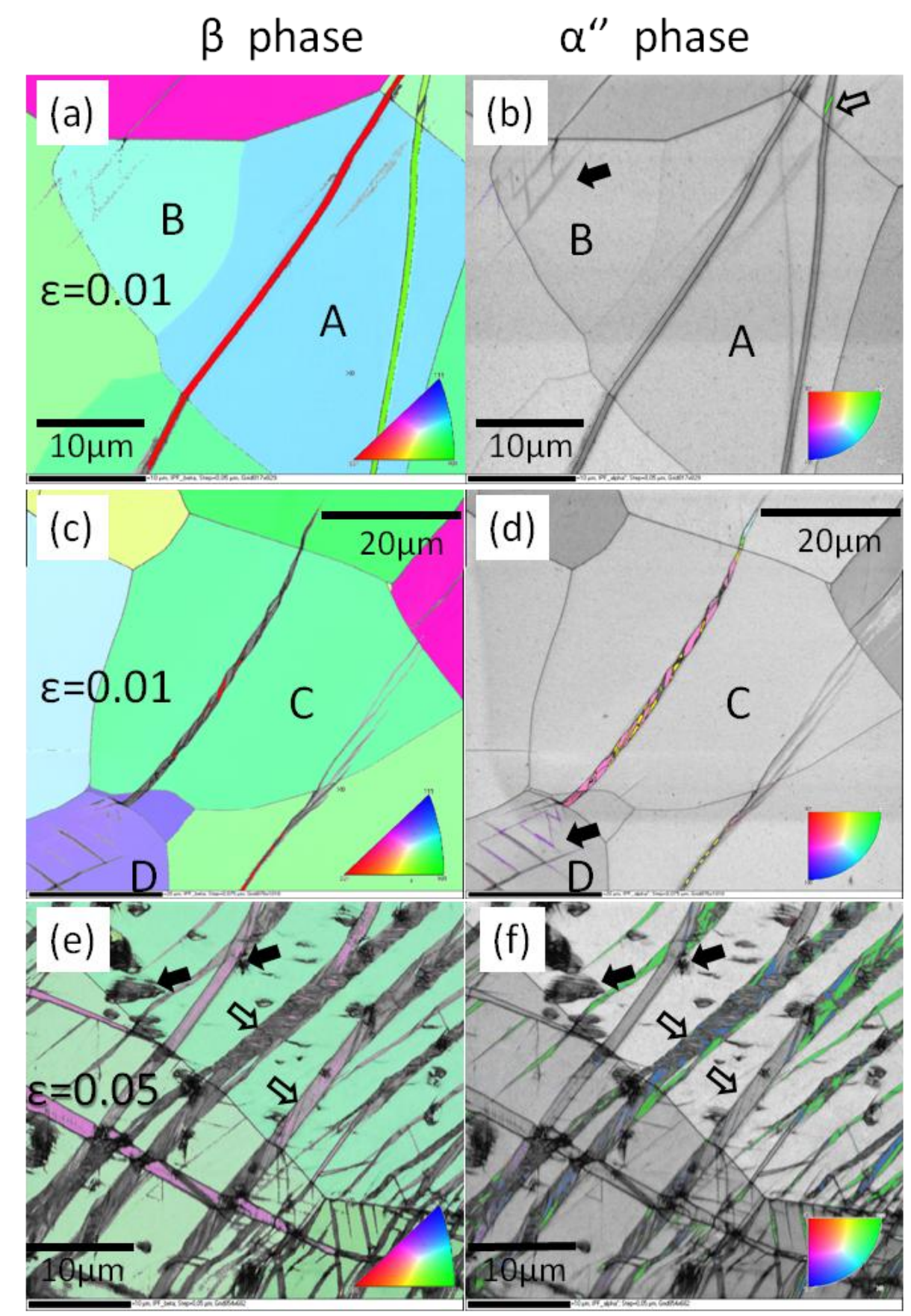

Figure 3. EBSD superimposed band contrast and inverse pole figure maps showing complex deformation patterns within different grains at $\varepsilon=0.01$ and $\varepsilon=0.05$. (a) Two $\{332\}<113>$ twins with different orientations crosses several grains; (b) Needle-like $\alpha$ " martensite grains in the $\beta$ matrix are indicated by a black arrow, while a grain of $\alpha$ " martensite within the twin band is indicated by an open arrow; (c) Several nanoscale $\{332\}<113\rangle$ twins are arranged to form complex deformation bands; (d) Two variants of $\alpha$ " martensite are forming deformation bands while needle-like $\alpha$ " martensite precipitates are indicated by a black arrow; (e) complex deformation pattern presenting $\{332\}<113>$ twins at $\varepsilon=0.05$; (f) Two variants of $\alpha$ " martensite are also present in the complex deformation pattern at $\varepsilon=0.05$. 

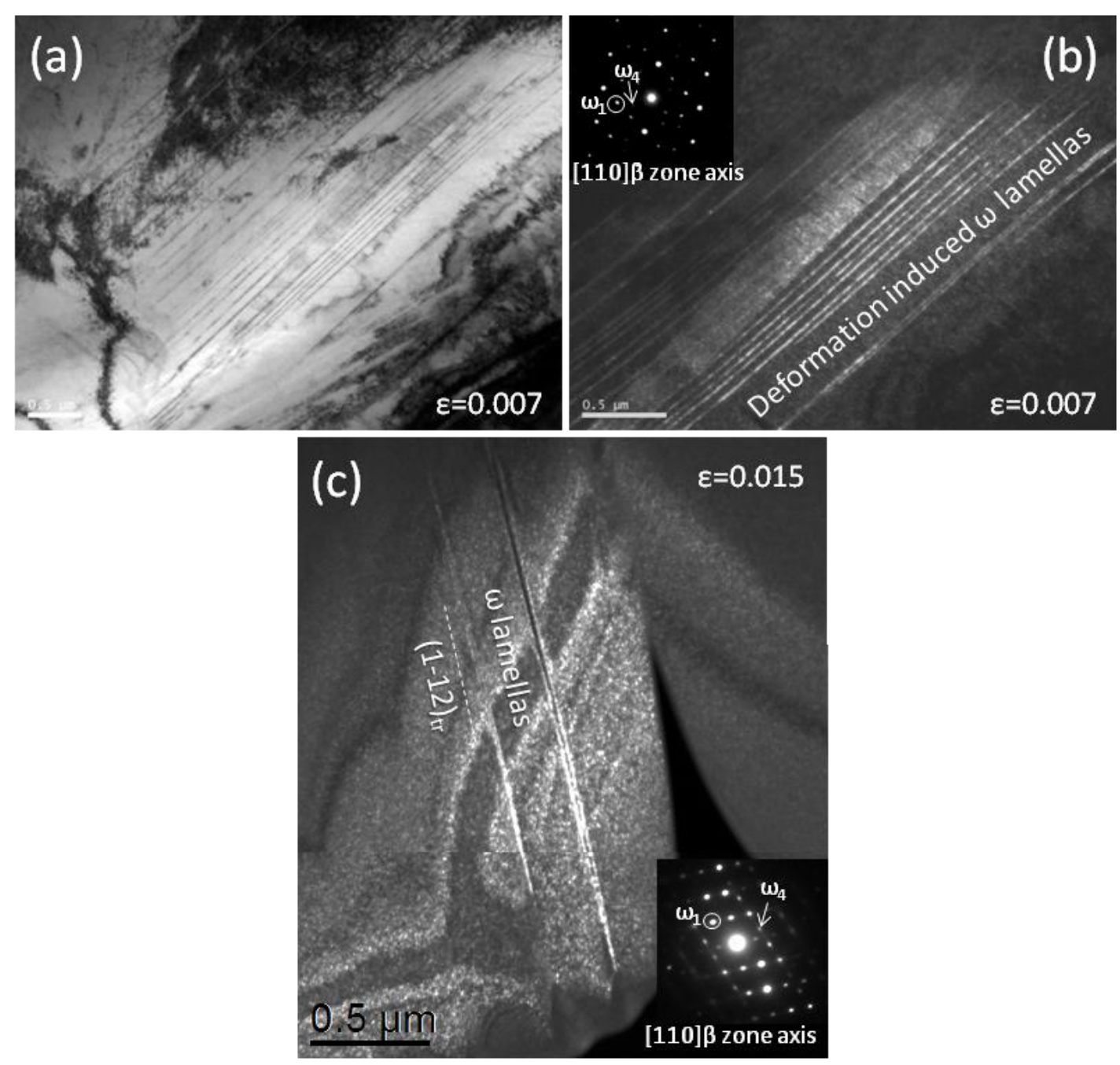

Figure 4. TEM images of the deformation induced $\omega$ phase at $\varepsilon=0.007$ and $\varepsilon=0.015$. (a)

Bright-field image at $\varepsilon=0.007$; (b) Dark-field image of the deformation induced $\omega$ lamellas at $\varepsilon=0.007$; (c) Dark-field image of the deformation induced $\omega$ lamella at $\varepsilon=1.5 \%$. The corresponding diffraction patterns are presented in the insets of each dark-field image, showing a difference of the diffraction intensity between the two variants $\left(\omega_{1}\right.$ and $\omega_{4}$ of the 4 variants $)$ of $\omega$ precipitates. 


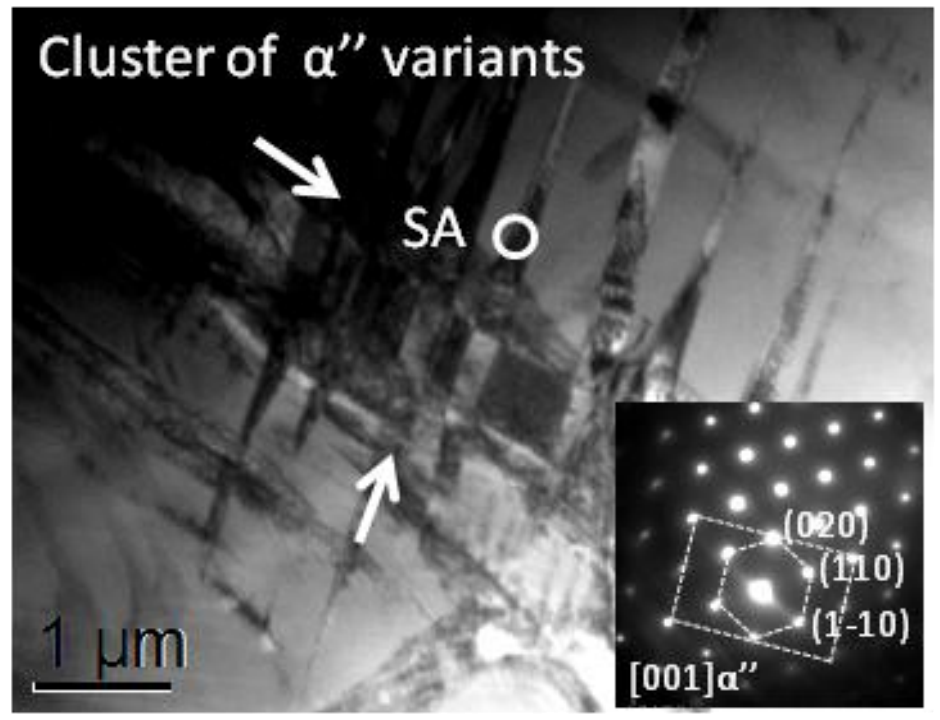

Figure 5. Bright-field TEM image of deformation feature identified as a cluster of $\alpha$ " variants. The corresponding SAED pattern is given in the inset. 

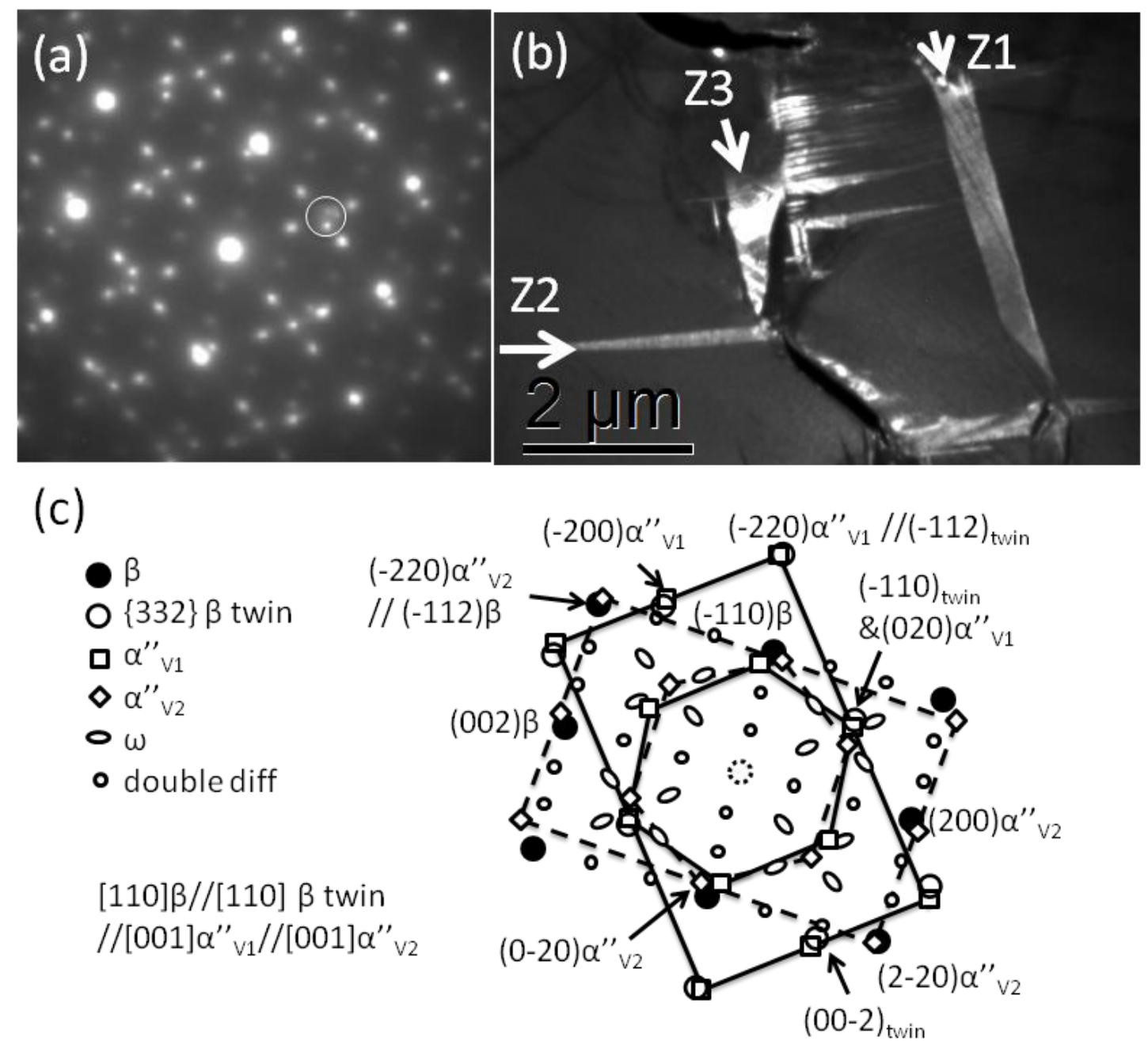

Figure 6. TEM images of a sample deformed to $\varepsilon=0.015$. (a) Diffraction pattern exhibiting multiple phases; (b) corresponding dark field image of the deformation products by selecting the diffraction spots highlighted on (a). Three morphologies of the deformation products are revealed, labeled as Z1, Z2 and Z3. (c) Indexed diagram corresponding to $\{332\} \beta$ twinning, $\omega$ phase and two kinds of $\alpha$ " martensite, noted as $\alpha "{ }_{\mathrm{v} 1}$ and $\alpha$ " ${ }_{\mathrm{V} 2}$. 

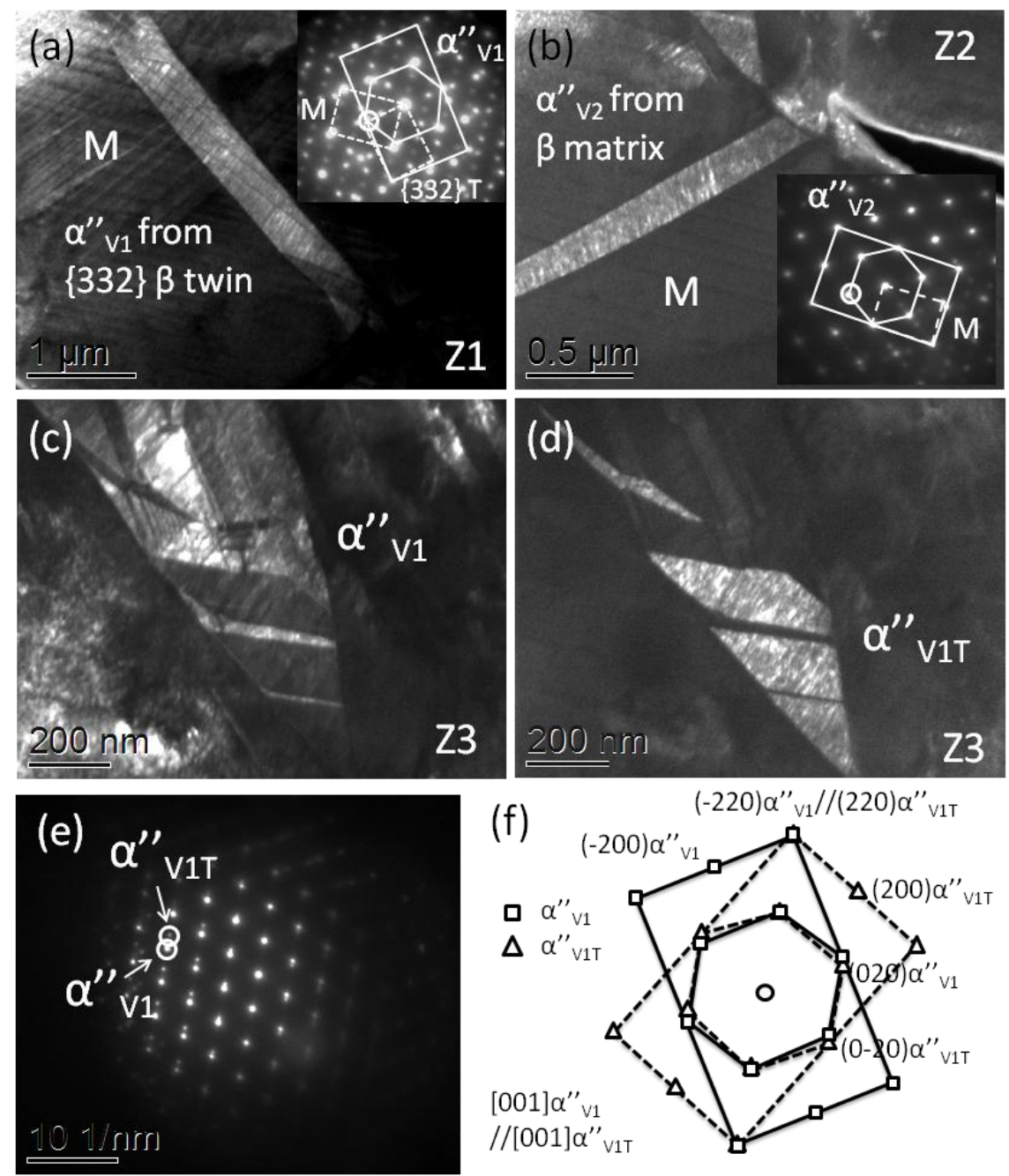

Figure 7. Detailed TEM micrographs of the zones Z1, Z2 and Z3 indicated on Figure 7. (a) Dark field image and corresponding diffraction pattern (inset) of zone $\mathrm{Z} 1$ showing a $\{332\} \beta$ twin which is almost fulfilled with $\alpha$ " ${ }_{\mathrm{V} 1}$ martensite; (b) Dark field image and corresponding diffraction pattern of zone Z2 showing a plate-like $\alpha$ " ${ }_{\mathrm{v} 1}$ martensite with conventional crystallographic relationship to $\beta$ matrix; (c) Dark field image of $\alpha$ " ${ }_{\mathrm{v} 1}$ martensite in zone Z3 presenting a twin relationship; (d) Dark field image of the morphology of the twinned $\alpha$ " ${ }_{\mathrm{V} 1}$ martensite at zone Z3, denoted by $\alpha$ " ${ }_{1 T}$; (e) diffraction pattern corresponding to zone Z3 showing the twin relationship between $\alpha{ }_{{ }_{\mathrm{V} 1}}$ and $\alpha{ }_{\mathrm{V} 1 \mathrm{~T}}$; (f) calculated diffraction pattern corresponding to zone $\mathrm{Z} 3$ highlighting the conventional $\{110\} \alpha "$ twinning relationship of the martensite. 

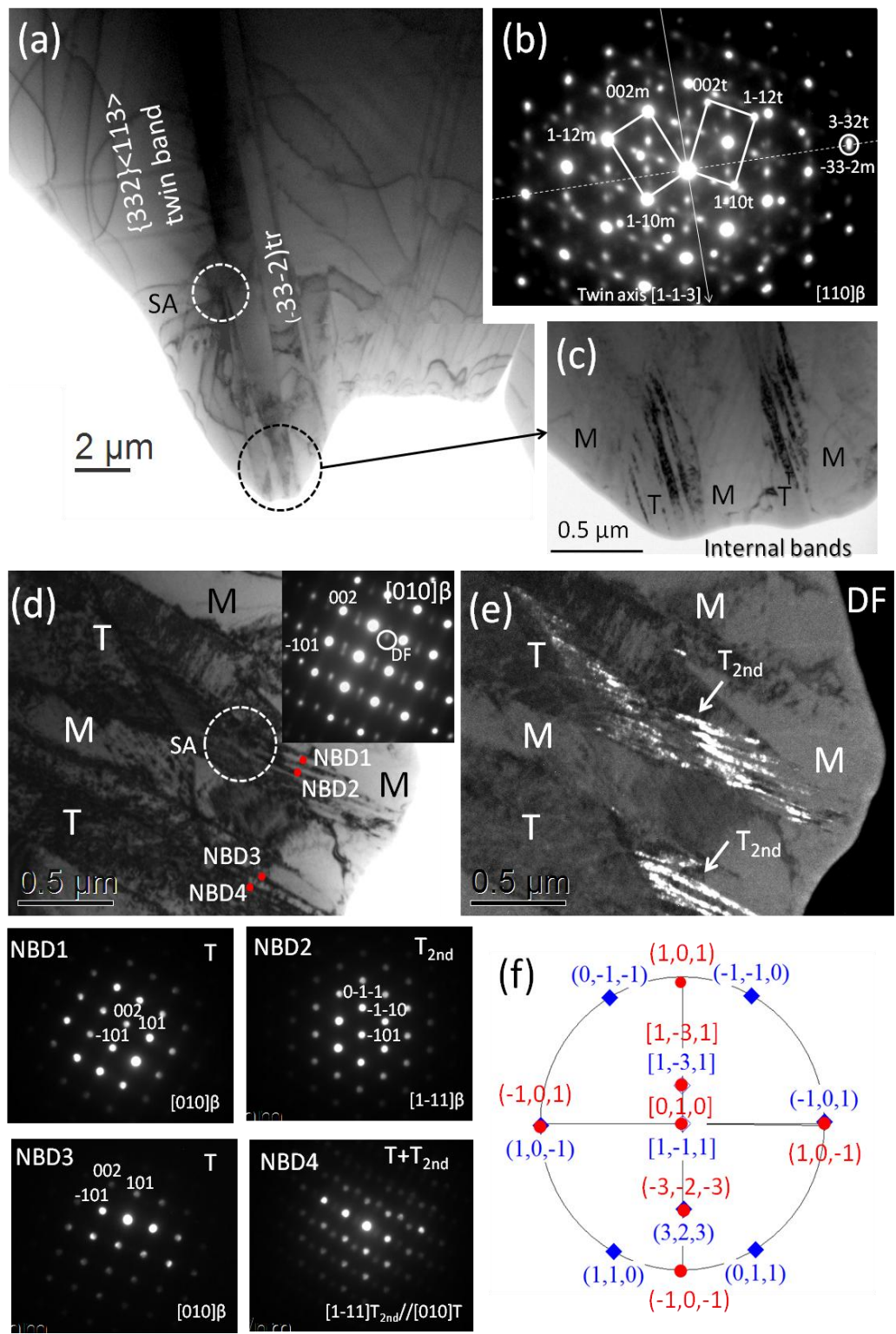

Figure 8. TEM images of major deformation features. (a) Bright-field image of a set of $\{332\}<113>$ twin bands; (b) The corresponding SAED pattern illustrates twinning plane and twinning axis; (c) The magnified region shows the sub-structures of fine internal bands; (d) Bright-field image of the region after rotating and tilting the specimen. Corresponding SAED pattern is shown in the inset. Nano-beam diffractions (NBD) were performed on the nano-bands indicated by red dots; (e) Dark-field image in twin spot (DF) of the secondary twins marked by $\mathrm{T}_{2 \mathrm{nd}}$; (f) A schematic stereo projection figure to illustrate the crystallographic relationship of internal $\{332\}<113>$ twin layers along zone axis $[010] / /[1-11]$ beta. 

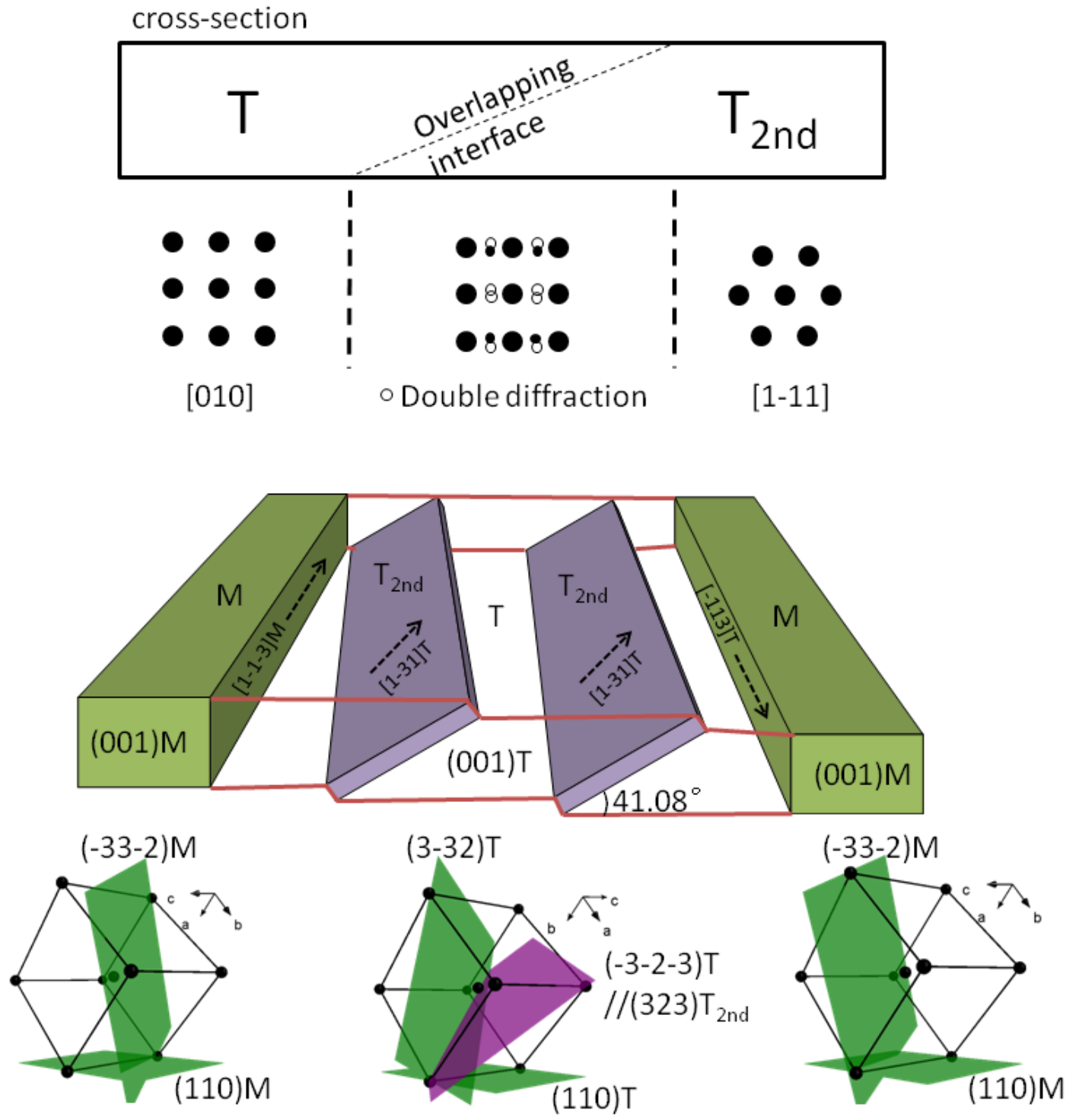

Figure 9. Schematic illustration of the structural relationship between the $\beta$ matrix $(M)$, the $\{332\}<113>$ twin band $(\mathrm{T})$ and nano-size internal twinning lamella $\left(\mathrm{T}_{2 \mathrm{nd}}\right)$. The overlapping of $\mathrm{T}$ and $\mathrm{T}_{2 n d}$ contributes to the double diffraction in the SAED pattern. 


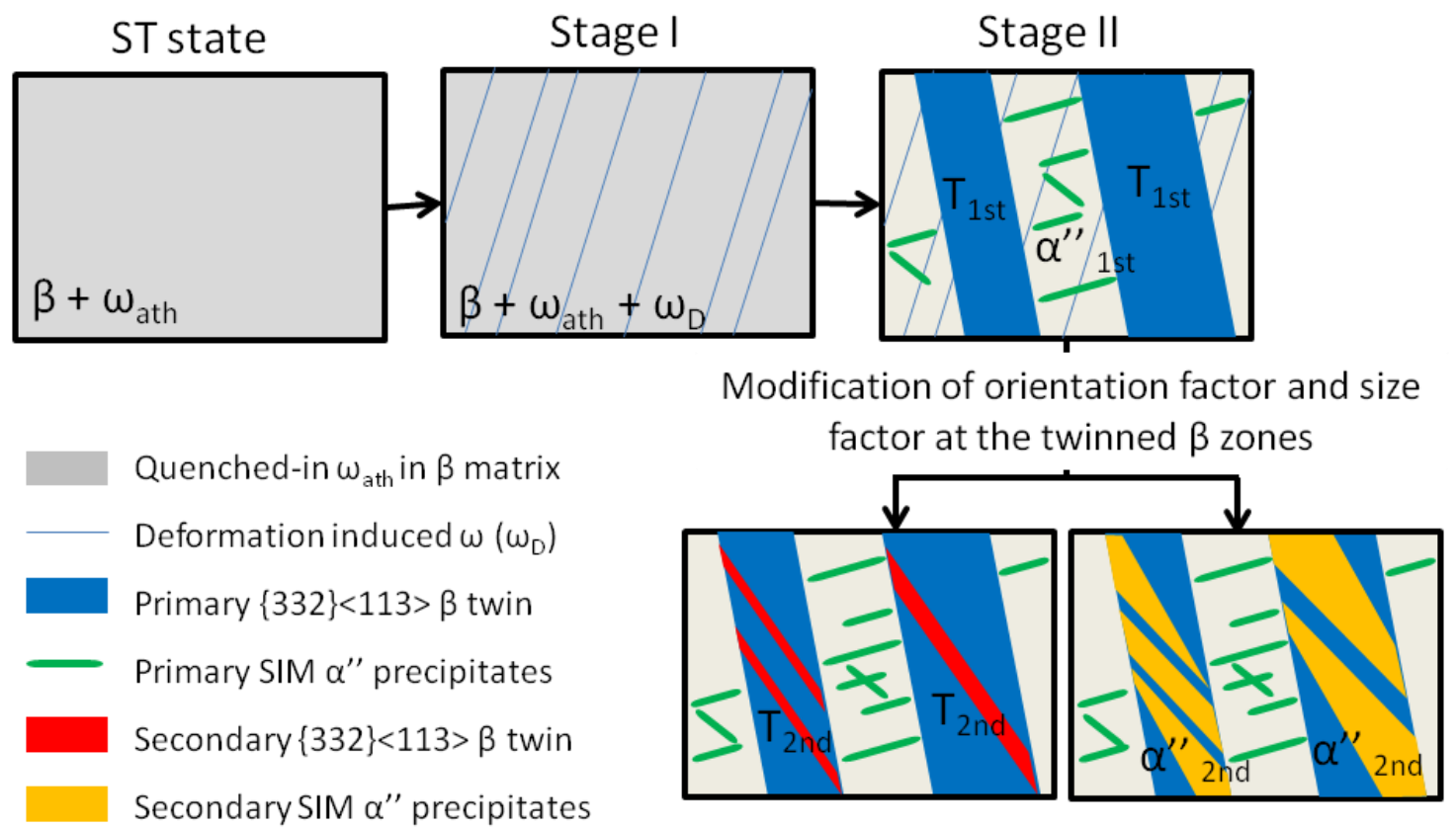

Figure 10. Schematic illustration of the evolution of the microstructure of the Ti-12Mo alloy when deformed in tension. The activation sequence of different deformation mechanisms are shown from ST state to the early deformation stages (Stages I and II), i.e. deformation induced $\omega$ phase, mechanical twinning and SIM $\alpha "$. The secondary deformation twins and SIM $\alpha$ " phase are denoted with subscript "2nd". 